\title{
Role of Distal loopogram Before Defunctioning Stoma Reversal- Results From An Indian Tertiary-Care Center
}

\author{
*Girish K Kundagulwar ${ }^{1}$, Vishwas D Pai ${ }^{1}$, Supreeta Arya ${ }^{2}$, Prachi Patil ${ }^{3}$ and Avanish P Saklani ${ }^{1}$ \\ ${ }^{1}$ Department of Surgical Oncology, Tata Memorial Centre, India \\ ${ }^{2}$ Department of Radio diagnosis, Tata Memorial Centre, India \\ ${ }^{3}$ Department of Digestive Diseases and Clinical Nutrition, Tata Memorial Centre, India
}

Submission: August 10, 2016; Published: August 29, 2016

"Corresponding author: Girish K Kundagulwar, Department of Surgical Oncology, Tata Memorial Centre, Mumbai 400012, Maharashtra, India.

\begin{abstract}
Aim: To determine the utility of routine distal loopogram before stoma reversal and its impact on the management of patients with a low rectal anastomosis.

Methods: This is a retrospective review of a prospectively maintained database of the patients underwent stoma reversal between June 1, 2011, and July 31, 2015. Primary variable assessed was accuracy of findings on preoperative distal loopogram in predicting postoperative complications after stoma reversal. Secondary variable was accuracy of findings on colonoscopy in predicting postoperative complications after stoma reversal.

Results: One hundred fifty-seven patients who underwent stoma reversal were included in the study. Distal loopogram was found to be abnormal in 23 patients (15\%). Overall, 17 patients developed postoperative complication in the form of anastomotic leakage or subacute intestinal obstruction. Colonoscopy report was available in 68 patients. All patients with an abnormality on colonoscopy developed postoperative complication where only $12 \%$ of patients with an abnormal distal loopogram developed a postoperative complication.
\end{abstract}

Conclusion: Distal loopogram is not accurate in assessment of anastomotic integrity and a contrast enema may be an alternative.

Keywords: Stoma Reversal; Distal Loopogram; Colonoscopy

\section{Introduction}

Radical surgery with total or partial tumor-specific mesorectal excision remains the mainstay of treatment for rectal cancers. Development of the anastomotic leakage is the most feared postoperative complication after rectal cancer surgery with incidence in the published literature ranging from 1.8 to $19.8 \%$ [1-2]. Advances in the management in the form of neoadjuvant chemoradiotherapy, staging with magnetic resonance imaging, availability of staplers, acceptance of lessextensive distal margins, and improved perioperative care have lead to increase in the number of low and ultralow anterior resections being performed all around the world. Literature suggests that presence of a defunctioning stoma decreases the incidence and the severity of anastomotic leakage and is recommended in all patients undergoing low anastomosis after proctectomy [3-4].
As a result, there has been a significant increase in the number of defunctioning stoma performed.It is well known that defunctioning stomas lead to inferior quality of life and causes major psychological handicap for the patient [5]. As a result, main aim while creating a stoma is to ensure its reversal at 6-12 weeks after the initial surgery. However, scheduling of reversal is extremely variable among various institutions [6]. Before stoma reversal, the distal anastomosis is routinely evaluated to rule out anastomotic leak or stricture by digital rectal examination, proctoscopy, and distal loopogram. This is important as postoperative morbidity ranging from 3 to $40 \%$ and mortality ranging from 0 to $4 \%$ after stoma reversal have been reported in literature [7-9].

The use of distal loopogram to confirm the anastomotic integrity before stoma reversal is still controversial. Literature is divided with some studies recommending the routine use 
of distal loopogram whereas others reserving it only for those cases with clinical suspicion of anastomotic dehiscence [1013]. This study was designed to determine the utility of routine distal loopogram before stoma reversal and its impact on the management of patients with a low rectal anastomosis.

\section{Methods}

This is a retrospective review of a prospectively maintained database in the Division of Colorectal Surgery at the Tata Memorial Centre, Mumbai, Maharashtra, India. Between June 1, 2011, and July 31, 2015, all patients who underwent stoma reversal were identified from this database. All patients who underwent initial defunctioning stoma for rectal adenocarcinoma and then stoma reversal in our institute after completion of treatment were included in the study.

Exclusion criteria were:

a. those who underwent defunctioning stoma for other indications;

b. those who underwent stoma reversal at peripheral centers.

Stoma reversal was planned after the completion of adjuvant chemotherapy or 6 weeks after initial surgery for those who did not receive adjuvant therapy. All patients were subjected to distal loopogram and complete colonoscopy (for those whose initial colonoscopy was incomplete) after detailed history and physical examination. Anal manometry was performed selectively whenever intersphincteric resection was performed or when anal sphincter tone was found to be reduced. Patients with normal distal loopogram, normal basal and squeeze pressure on manometry, and no other lesions on colonoscopy were planned for stoma reversal. When basal pressure was reduced or squeeze pressure was not sustained on anal manometry, pelvic floor exercises were advised for 3 to 6 weeks, followed by reassessment for stoma reversal. Those with stricture at anastomotic site on distal loopogram or physical examination were further evaluated with colonoscopy and biopsy from the stricture to rule out local recurrence. Once local recurrence was ruled out, stricture was dilated, followed by stoma reversal.

Stoma reversal was performed by a circumferential incision. The anastomotic technique used was a hand-sewn end-to-end anastomosis with or without resection, a handsewn side-to-side with resection, or a stapled anastomosis. Closure of the abdominal wall was performed with Vicryl 2-0, and skin was closed with interrupted Ethilon 3-0 sutures. Anastomotic leakage was defined clinically as features of intra abdominal sepsis or radiologically as anastomotic leakage of contrast or any perianastomotic collection requiring drainage. Exploratory laparotomy followed by reanastomosis and proximal defunctioning ileostomy were performed for those with hemodynamic instability.
Primary variable assessed was accuracy of preoperative distal loopogram in accurately predicting anastomotic healing. Secondary variable was accuracy of findings on colonoscopy in predicting postoperative complications after stoma reversal. Statistical analysis was performed using SPSS 20.0 for Windows (SPSS, Inc., Chicago, IL); $\chi 2$ test or Fisher's exact test, as appropriate, was used to determine the primary variable of interest. The difference was considered significant if the $\mathrm{p}$ value was less than 0.05 .

\section{Results}

Table 1: Demographic characteristics of the patients included in the study.

\begin{tabular}{|c|c|}
\hline Demographic Characteristics & Patients (n = 157), n (\%) \\
\hline Age (years), median (range) & $48(19-83)$ \\
\hline \multicolumn{2}{|c|}{ Sex } \\
\hline Male & $59(63)$ \\
\hline Female & $58(37)$ \\
\hline AR & $62(39.5)$ \\
\hline LAR & $72(45.9)$ \\
\hline ISR & $23(14.6)$ \\
\hline \multicolumn{2}{|c|}{ Type of anastomosis } \\
\hline Stapled & $134(85.4)$ \\
\hline Hand sewn & $23(14.6)$ \\
\hline Stoma type & $79(50)$ \\
\hline Colostomy & $78(50)$ \\
\hline Ileostomy & $22(14)$ \\
\hline \multicolumn{2}{|c|}{ Timing of stoma } \\
\hline $\begin{array}{c}\text { Before NACTRT } \\
\text { Postoperatively for anastomotic } \\
\text { leakage }\end{array}$ & $126(80)$ \\
\hline During primary surgery & $9(6)$ \\
\hline median (range) & $46-178)$ \\
\hline
\end{tabular}

One hundred fifty-seven patients were included in the study. Demographic characteristics are shown in Table 1. The median time from stoma creation to closure was 45 weeks (range, 6-178 weeks). Among the patients included in the study, 23 patients showed stricture on distal loopogram (15\%), whereas rest $(134$ [85\%] patients) showed normal findings. Among 23 patients with stricture, 2 patients developed postoperative complications. One patient developed collection in pelvis, which was drained with a pigtail, and the other patient developed subacute intestinal obstruction (SAIO), which was managed conservatively.

Colonoscopy report was available for 68 patients included in this series. Indication for colonoscopy was either incomplete colonoscopy before initial surgery because of the obstructing growth or an abnormality on distal loopogram. Among these, 27 patients revealed abnormality on colonoscopy in the form of luminal narrowing. Five patients in this subgroup developed 


\section{Cancer Therapy \& Oncology International Journal}

postoperative complications: one patient developed anastomotic leak, one developed pelvic collection without any obvious leak, and three patients developed SAIO (Table 2).

Table 2: Details of findings on X-ray loopogram, colonoscopy, and postoperative morbidity.

\begin{tabular}{|c|c|}
\hline \multicolumn{2}{|c|}{ Outcomes } \\
\hline \multicolumn{2}{|c|}{ X-ray loopogram } \\
\hline Normal & $134(85)$ \\
\hline Abnormal & $23(15)$ \\
\hline \multicolumn{2}{|c|}{ Colonoscopy (n = 68) } \\
\hline Normal & $41(60)$ \\
\hline Abnormal & $27(40)$ \\
\hline Postoperative complication after stoma closure \\
\hline Yes & $17(11)$ \\
\hline No & $140(89)$ \\
\hline
\end{tabular}

Among the 23 patients with abnormal distal loopogram, colonoscopy report was not available in 4 patients, whereas the remaining 19 patients showed luminal narrowing. Among the 27 patients with luminal narrowing on colonoscopy, 11 patients revealed normal distal loopogram whereas rest showed stricture. Among the 11 patients who showed abnormality on colonoscopy but normal distal loopogram, 4 patients developed postoperative complications (one anastomotic leak and three SAIOs). Among the three patients who showed abnormality on distal loopogram but normal colonoscopy, none developed postoperative complications.

Twelve $(7.6 \%)$ patients included in this series showed anastomotic leakage after the initial surgery. Among these, 5 patients $(42 \%)$ revealed narrowing whereas rest (58\%) showed normal findings on distal loopogram. None of the patients in the former group developed postoperative complications, whereas one patient in the latter group developed anastomotic leakage after stoma reversal.

\section{Discussion}

Anastomotic leakage is the most feared complication after rectal cancer surgery. Studies have shown that proximal defunctioning stoma reduces the incidence and severity of the anastomotic leakage. However, it is of prime importance to ensure safe and timely stoma reversal to improve quality of life of the patients. There are three ways to assess anastomotic integrity before stoma reversal-contrast enema, distal loopogram, and colonoscopy. Distal loopogram has been the routine investigation before stoma reversal, and this study was designed to determine its usefulness.

Contrast enema compared with distal loopogram or colonoscopy does not require any special preparation and can be performed as a day care procedure. In contrast, distal loopogram requires distal loop washes which are both labor intensive and time consuming. Some investigators have found that contrast enema is objective and is effective in excluding clinically significant anastomotic problems [10-14]. In contrast, others have found that contrast enema does not provide any additional information when digital rectal examination and proctoscopy show normal findings [11-15].

In addition, findings on contrast enema may be difficult to interpret, particularly in the presence of a pouch or a "dog-ear" from a coloanal anastomosis. In contrast to distal loopogram or colonoscopy, it allows visualization of limited portions of colon.

Distal loopogram, in addition to testing the integrity of the anastomosis, visualizes the entire colon to detect any other lesions. However, in this series, none of the patients were found to have any other lesion in the rest of the colon on distal loopogram. In this series, among the 17 patients who developed postoperative complications, distal loopogram was abnormal in 2 patients, whereas in the rest, it was normal. Hence, distal loopogram did not predict postoperative morbidity in majority of patients. Distal loopogram requires distal loop wash and, hence, is labor intensive. Barium peritonitis, although rare, is associated with significant morbidity and mortality [16-17].

Selective use of contrast studies in high-risk patients has been reported in two previous studies [12-13]. In this study, 12 patients had developed anastomotic leakage after the initial surgery. Among these patients, five patients with abnormal finding on distal loopogram did not develop postoperative complication. In contrast, the only patient in this subgroup who developed anastomotic leakage after stoma reversal showed normal findings on distal loopogram. This fact is contradictory to a previous study, which suggested that preoperative distal loopogram should be considered in patients with an ileostomy constructed after anastomotic leakage. However, Hong et al. [18] also did not find preoperative distal loopogram much useful in patients with an ileostomy constructed after anastomotic leakage.

Tong et al. [19], in their attempt to determine an alternative to contrast studies, found that false-positive and false-negative rates of contrast enema were $6.4 \%$ and $3.5 \%$, respectively. They concluded that digital rectal examination by an experienced surgeon yields more useful clinical information than the contrast studies [19].

Table 3: Accuracy of X-ray loopogram and colonoscopy in predicting postoperative complication after stoma reversal

\begin{tabular}{|c|c|c|}
\hline Investigations & $\begin{array}{c}\text { Postoperative } \\
\text { complication, } \mathbf{n}(\%)\end{array}$ & $p$ value ( $x^{2}$-test) \\
\hline \multicolumn{3}{|c|}{ X-ray loopogram $(n=157)$} \\
\hline Normal & $15(88)$ & \multirow{2}{*}{1} \\
\hline Abnormal & $2(12)$ & \\
\hline \multicolumn{3}{|c|}{ Colonoscopy $(n=68)$} \\
\hline Normal & 0 & \multirow{2}{*}{0.003} \\
\hline Abnormal & $6(100)$ & \\
\hline
\end{tabular}




\section{Cancer Therapy \& Oncology International Journal}

In this study, it was found that colonoscopy was more accurate in predicting postoperative complications after stoma reversal (Table 3). In addition, it allows visualization of the entire colon and, hence, can detect synchronous primaries and polyps. Results of SIGGAR trial have shown CT colonography to be more sensitive than double contrast enema for detecting polyps as well as cancers [20].

A single contrast loopogram is unlikely to be good enough to detect neoplasms in the colon. However, in view of the retrospective nature of the study, colonoscopy finding were available in limited number of patients, and indication for performing colonoscopy in some or omitting it in others could not be determined. Literature on the role of colonoscopy before stoma reversal is limited although it can visualize the entire colon and may detect additional lesions including polyps and synchronous malignancies.

Limitations of this series is the retrospective nature of the study and, hence, the associated selection bias, lack of documentation of findings on digital rectal examination for patients with abnormal distal loopogram, and absence of colonoscopy report in more than half of the patients.

\section{Conclusion}

Distal loopogram is not accurate in assessment of anastomotic integrity, and a contrast enema may be an alternative. Hence either a flexible sigmoidoscopy or a gastrograffin enema to visualize the anastomosis is recommended.

\section{References}

1. Choi HK, Law WL, Ho JWC (2006) Leakage after resection and intraperitoneal anastomosis for colorectal malignancy: analysis of risk factors. Dis Colon Rectum 49(11): 1719-1725.

2. Platell C, Barwood N, Dorfmann G, Makin G (2007) The incidence of anastomotic leaks in patients undergoing colorectal surgery. Colorectal Dis 9(1): 71-79.

3. Gu W, Wu S (2015) Meta-analysis of defunctioning stoma in low anterior resection with total mesorectal excision for rectal cancer: evidence based on thirteen studies. World J Surg Oncol 13: 9.

4. Jatal S, Pai V, Demenezes J, Desouza A, Saklani A, et al. (2015) Analysis of risk factors and management of anastomotic leakage after rectal cancer surgery: an Indian series. Indian J Surg Oncol7(1): 1-7.

5. O'Leary DP, Fide CJ, Foy C, Lucarotti ME (2001) Quality of life after low anterior resection with total mesorectal excision and temporary loop ileostomy for rectal carcinoma. Br J Surg 88(9): 1216-1220.

6. David GG, Slavin JP, Willmott S, Corless DJ, Khan AU ( 2010) Loop ileostomy following anterior resection: is it really temporary Colorectal Dis 12(5): 428-432.
7. D'Haeninck A, Wolthuis AM, Penninckx F, D'Hondt M, D'Hoore A, et al. (2011) Morbidity after closure of a defunctioning loop ileostomy. Acta Chir Belg 111(3): 136-141.

8. Mengual-Ballester M, García-Marín JA, Pellicer-Franco E, GuillénParedes MP, García-García ML, et al. (2012) Protective ileostomy: complications and mortality associated with its closure. Rev Esp Enferm Dig 104(7): 350-354.

9. Chow A, Tilney HS, Paraskeva P, Jeyarajah S, Zacharakis E, et al. (2009) The morbidity surrounding reversal of defunctioning ileostomies: a systematic review of 48 studies including 6,107 cases. Int J Colorectal Dis 24(6): 711-723.

10. Dolinsky D, Levine MS, Rubesin SE, Laufer I, Rombeau JL, et al. (2007) Utility of contrast enema for detecting anastomotic strictures after total proctocolectomy and ileal pouch-anal anastomosis. AJR Am J Roentgenol 189(1): 25-29.

11. da Silva GM, Wexner SD, Gurland B, Gervaz P, Moon SD, et al. (2004) Is routine pouchogram prior to ileostomy closure in colonic J-pouch really necessary? Colorectal Dis 6(2): 117-120.

12. Brown JJ, Balfe DM, Heiken JP, Becker JM, Soper NJ, et al. (1990) Ileal J pouch: radiologic evaluation in patients with and without postoperative infectious complications. Radiology 174(1): 115-120.

13. Thoeni RF, Fell SC, Engelstad B, Schrock TB (1990) Ileoanal pouches: comparison of CT, scintigraphy, and contrast enemas for diagnosing postsurgical complications. AJR Am J Roentgenol 154(1): 73-78.

14. Habib K, Gupta A, White D, Mazari FAK, Wilson TR, et al. (2015) Utility of contrast enema to assess anastomotic integrity and the natural history of radiological leaks after low rectal surgery: systematic review and meta-analysis. Int J Colorectal Dis 30(8): 1007-1014.

15. Larsson A, Lindmark G, Syk I, Buchwald P (2015) Water soluble contrast enema examination of the integrity of the rectal anastomosis prior to loop ileostomy reversal may be superfluous. Int J Colorectal Dis 30(3): $381-384$.

16. Gelfand DW. (1980) Complications of gastrointestinal radiologic procedures: I. Complications of routine fluoroscopic studies. Gastrointest Radiol 5(4): 293-315.

17. Dellinger RP, Levy MM, Rhodes A, Annane D, Gerlach H, et al. (2013) Surviving sepsis campaign: international guidelines for management of severe sepsis and septic shock, 2012. Intensive Care Med 39(2): 165-228.

18. Hong SY, Kim DY, Oh SY, Suh KW (2012) Routine barium enema prior to closure of defunctioning ileostomy is not necessary. J Korean Surg Soc 83: 88-91.

19. Tang CL, Seow-Choen F (2005) Digital rectal examination compares favourably with conventional water-soluble contrast enema in the assessment of anastomotic healing after low rectal excision: a cohort study. Int J Colorectal Dis 20(3): 262-266.

20. Halligan S, Wooldrage K, Dadswell E, Kralj-Hans I, von Wagner C, et al (2013) Computed tomographic colonography versus barium enema for diagnosis of colorectal cancer or large polyps in symptomatic patients (SIGGAR): a multicentre randomised trial. Lancet 6 381(9873): 11851193. 